\title{
Malaria vector species composition and relative abundance in Mutare and Mutasa districts, Zimbabwe
}

\author{
S. Sande, ${ }^{1}$ M. Zimba, ${ }^{1}$ P. Chinwada, ${ }^{1}$ H.T. Masendu, ${ }^{2}$ A. Makuwaza ${ }^{3}$ \\ ${ }^{1}$ Department of Biological Science, University of Zimbabwe, Harare; ${ }^{2}$ Abt Associates Inc., Mount \\ Pleasant, Harare; ${ }^{3}$ National Institute of Health Research, Harare, Zimbabwe
}

\begin{abstract}
Regular entomological monitoring is important to determine changes in mosquito species composition and relative densities of malaria vectors in relation to vector control interventions. A study to gain insights into malaria vector species composition and relative
\end{abstract}

Correspondence: Shadreck Sande, 2557 Glaudina Park, Harare, Zimbabwe. Tel.: +2634.304.702 - Mobile: +263.773 .031 .291 - Fax: +2634.798 .566 .

E-mail: shadrecksande@rocketmail.com

Key words: Abundance; anopheline; mosquito; species.

Contributions: SS, conception of the problem, design, collection, PCR assays, analysis, interpretation and drafting of final article; MZ, PC, and HTM, responsible for all the stages of the research, including analysis and interpretation as well as critically reviewing the final draft for academic worth; AM, data collection, PCR assays, analysis, interpretation and drafting of final article.

Acknowledgements: the authors would like to thank the University of Zimbabwe for providing learning facilities, Mr. Nzira Lukwa, Medical Entomologist for the National Institute of Health Research for providing equipment for mosquito collection and Dr. J. Mberikunashe, National Malaria Control Programme Manager for providing vehicle for field work as well as the communities in Mutare and Mutasa districts for allowing the collection of mosquitoes in their houses.

Funding: the National Malaria Control Programme funded this research project.

Conflict of interest: the authors declare no potential conflict of interest.

Conference presentation: this paper was presented at Zimbabwe National Malaria Conference, 2014 September 1-4, Kadoma, Zimbabwe.

Received for publication: 13 Janaury 2015.

Revision received: 20 June 2015.

Accepted for publication: 20 June 2015.

(C) Copyright S. Sande et al., 2015

Licensee PAGEPress, Italy

Journal of Entomological and Acarological Research 2015; $47: 4955$

doi:10.4081/jear.2015.4955

This article is distributed under the terms of the Creative Commons Attribution Noncommercial License (by-nc 3.0) which permits any noncommercial use, distribution, and reproduction in any medium, provided the original author(s) and source are credited. abundance was undertaken in Mutare and Mutasa districts, Zimbabwe. Two methods; indoor resting catches and larval sampling were used to collect indoor resting adults and larvae from May 2013 to April 2014. Mosquitoes collected as adults and reared from larvae that were identified morphologically as potential malaria vectors were further processed to sibling species by polymerase chain reaction (PCR). Morphological identification of anopheline mosquitoes showed presence of two complexes: An. funestus and An. gambiae. The total number of female members of the An. funestus group and An. gambiae complex collected by both methods from the two sites was 840 and 31 respectively. Malaria vector species of both complexes were more abundant in Mutare than in Mutasa. The PCR-based assays showed the presence of four sibling species: An. funestus sensu stricto $(90.8 \%$, 267/294) and An. leesoni (5.1\%, 15/294), of An. funestus group; An. arabiensis $(41.9 \%, 13 / 31)$ and An. quadriannulatus $(48.4 \%, 15 / 31)$ of the An. gambiae complex. About 4\% and 5\% of specimens of An. gambiae complex and An. funestus group respectively did not amplify. Of the two identified malaria vector sibling species, An. funestus sensu stricto was more abundant $(95.4 \%, 267 / 280)$ than An. arabiensis $(4.6 \%, 13 / 280)$, suggesting the replacement to secondary vector of An. arabiensis, which was previously the predominant vector species. An. funestus sensu stricto and An. arabiensis, the most important vectors of human malaria were identified in this study, but their resting and biting habits as well as insecticide susceptibility are unclear. Further studies on vector behaviour are therefore recommended.

\section{Introduction}

Malaria in Zimbabwe is a serious public health problem, causing morbidity, mortality and poverty although control efforts aimed at the vector mosquito are set up annually (Lukwa et al., 2014). The most important vector species of human malaria in Africa belong to An. gambiae complex and An. funestus group. In Zimbabwe, malaria is transmitted by vector species belonging to An. gambiae and An. funestus (Masendu et al., 2005). Members of the An. gambiae complex include eight sibling species: An. gambiae sensu stricto Giles, An. arabiensis Patton, An. bwambae White, An. melas Theobald, An. merus Dönitz, An. quadriannulatus Theobald, An. amharicus Hunt, Coetzee and Fettene and An. comorensis Brunhes, le Goff and Geoffroy. Within the complex, An. gambiae sensu stricto (hereafter referred to as An. gambiae) and An. arabiensis are the major human malaria vectors in sub-Saharan Africa (Gregory \& Yoosook, 2013).

Previous studies on An. gambiae complex in Zimbabwe documented four members; An. gambiae, An. arabiensis, An. merus and An. quadriannulatus in various combination of sympatry (Masendu et al., 2005). The wide distribution of An. arabiensis, often in association with the nonvector An. quadriannulatus, confirmed its status as the principal human 
malaria vector in Zimbabwe (Masendu et al., 2005; Munhenga, 2010).

Historically, the An. funestus group consists of at least nine African species: An. funestus sensu stricto (hereafter referred to as An. funestus), An. rivulorum, An. vaneedeni, An. leesoni, An. confusus, An. fuscivenosus, An. brucei, An. parensis and An. aruni (Gillies \& De Meillon, 1968; Gillies \& Coetzee, 1987). Recently, new sibling species including An. rivulorumlike (from West Africa), An. funestus-like (from Malawi) and An. funestuslike-like (from Zambia) (Spillings et al., 2009) have been isolated.

In the An. funestus group, An. funestus is the only member that is implicated as an important vector of malaria in sub-Saharan Africa (Coetzee et al., 2000). The sympatric occurrence of An. funestus with minor vectors An. rivulorum and An. leesoni has been found in several countries in Africa (Wilkes et al., 1996; Cohuet et al., 2003) but has not been reported in Zimbabwe.

The importance of the above vectors in malaria transmission differs depending on their feeding and resting preference behavior, seasonal abundance and vectorial capacity (Coluzzi, 1984). These differences therefore, contribute to the varied malaria epidemiological patterns observed in Africa and, subsequently, different vector behaviour may require different strategies for optimal vector control.

Currently, the two most common vector control strategies are indoor residual spraying (IRS) and long lasting insecticidal nets (LLINs), accounting for almost $60 \%$ of global investments in malaria control (WHO, 2013). Molineaux \& Gramiccia (1980) concluded that differences in vector behavior and insecticide resistance cause the failure of IRS and/or mosquito nets in suppressing malaria transmission in any setting. As such, different vector species may have different insecticide susceptibility status at any given locality and time, thus, insecticides for vector control need to be selected carefully to achieve maximum impact on malaria transmission.

Current vector control studies in Zimbabwe, especially on species composition and relative abundance in relation to malaria control focus mainly on members of the An. gambiae complex. This focus on only An. gambiae complex and marginalizing the An. funestus group may be due to fairly easy larval collection and adaptability of the An. gambiae complex to field insectary and laboratory conditions as well as the scarcity of members of the An. funestus group. The scarcity of An. funestus in Zimbabwe is believed to be associated with consistent implementation of IRS which commenced in the early 1950s and expanded in 1980s following national independence in 1980 and scaled up in the mid-1990s (Munhenga, 2010).

An. funestus was last reported about ten years ago by Masendu et al. (2005) only at Buffalo Ranch in Chiredzi district of Masvingo province in the southern region of Zimbabwe. More recently, it was reported in Honde Valley, Zimbabwe (Choi et al., 2014). Despite continued IRS programmes in place, there is a real possibility of An. funestus resurgence as the focus of entomological studies has been almost exclusively on the An. gambiae complex. Consequently, the current malaria species composition and densities, especially of An. funestus remain unknown in the study areas.

Up-to-date information on species composition and densities of both primary and secondary vectors is crucially needed to properly devise and implement vector control activities to prevent malaria transmission and to assess their effectiveness. Therefore, this study aimed to determine malaria vector species composition and relative abundance in Burma Valley and Zindi in Mutare and Mutasa districts, respectively.

\section{Materials and methods}

\section{Study areas}

The study was undertaken in Burma Valley administrative ward $\left(19^{\circ}\right.$ $\left.11^{\prime} \mathrm{S}, 32^{\circ} 48^{\prime} \mathrm{E}\right)$, Mutare district, and Zindi administrative ward $\left(18^{\circ}\right.$ 22 ' S, $32^{\circ} 56^{\prime}$ E), Mutasa district of Manicaland province, Zimbabwe (Figure 1). Studies were done from May 2013 to April 2014. The sites are situated in rural areas with similar ecological settings. The ecolog- ical features of the sites, however, show that they consist predominantly of tropical savanna, grassland and woodland ecosystem characterized by grass, trees and bushes, widely spaced and typically associated with the tropical wet and dry climate type.

The climate is tropical with annual temperature, relative humidity and rainfall ranges of $18-30^{\circ} \mathrm{C}, 65-85 \%$ and $900-1200 \mathrm{~mm}$, respectively (Taylor \& Mutambu, 1986). Additionally, the climate presents three clearly different seasons: a cold-dry season between April and August, with little rains in April and at times extremely cold in July, hot and dry season in August through to October, completely without rains, and a hot-wet season stretching from November to March with a potential of high rainfall during the months of December and February (Taylor \& Mutambu, 1986). Both sites are valleys (679 and 766 meters above sea level for Burma Valley and Zindi, respectively) with several streams and rivers that flow into Mozambique.

Majority of the community members are subsistence farmers who grow mainly maize, bananas and yams along the river banks. Income is derived from the sale of their agricultural produce in Mutare, Harare and Bulawayo urban markets. The farmers use mainly pyrethroid and organophosphate classes of insecticides to protect their crops against several agricultural pests.

Selection of study sites was based on the ecological conditions which are potential breeding sites for malaria vectors. Malaria transmission in the two study areas is a major public health problem and occurs seasonally, especially in November through to May with a peak in March/April (Lukwa et al., 2014). In June and July, the two sites experience the lowest malaria transmission (Lukwa et al., 2014).

Several strategies which included IRS, LLINs, larval source management, intermittent preventive treatment in pregnancy, diagnosis and case management as well as social behaviour change communication were put into action to control both the malaria vectors and parasites, to reduce malaria transmission in the study sites. Among these interventions, IRS, LLINs and malaria case management have been scaledup to cover most villages of the study areas (Lukwa et al., 2014).

\section{Mosquito larval sampling and rearing}

Weekly physical examinations of natural and human-made mosquito larval habitats were conducted to determine the availability of potential breeding sites for both An. gambiae sensu lato (s.l.) and An. funestus group for two months for five days per month from September to October 2013. Types of breeding sites were categorised into humanmade and natural in origin and recorded. Larval collection was performed once a month from November 2013 to April 2014. Where mosquito larvae were present, 5-10 dips, depending on the size of the habitat, were taken using standard dippers of $350 \mathrm{ml}$ capacity. Samples were classified into: i) group of $1^{\text {st }}$ and $2^{\text {nd }}$ instars; ii) group of $3^{\text {rd }}$ and $4^{\text {th }}$ of instars; and iii) pupae. The instars were identified morphologically using taxonomic keys of Gillies \& De Meillon (1968). The number of $1^{\text {st }}$ to $4^{\text {th }}$ instar larvae of each anopheline species collected per dip represented the larval density in each breeding site.

Immediately after morphological determination of species and larval density assessment, the Anopheles larvae were placed in plastic jugs and taken to entomological field laboratories/insectaries for rearing according to WHO (2003) guidelines. All larvae were kept at room temperature and fed with ground fish food. The adults that emerged were transferred to the laboratory at National Institute of Health Research (NIHR) in Harare. The specimens were killed by anaesthetizing with drops of acetyl acetate placed on a large filter paper that was held above the adults container. Emerged adults were identified morphologically into species complexes (An. gambiae and An. funestus) using taxonomic keys of Gillies \& Coetzee (1987). Afterwards, they were individually preserved on silica gel in well-labelled eppendorf tubes prior to polymerase chain reaction (PCR) assays. Other anophelines were morphologically identified (Gillies \& Coetzee, 1987), recorded and discarded. 


\section{Indoor collections}

Indoor resting adult mosquitoes were collected by the pyrethrum spray catch (PSC) method (WHO, 2003) in twenty conveniently selected bedrooms in Burma Valley and Zindi, ten bedrooms apiece for one day per month from May 2013 to April 2014. The selected bedrooms were visited between 6:30 and 10:00 a.m. every study day to collect adult mosquitoes. Anophelines were sorted and identified morphologically into An. gambiae s.l. and An. funestus group as well as other anophelines (Gillies \& Coetzee, 1987). Female specimens were preserved in labelled eppendorf tubes containing silica gel as drying agent awaiting further processing at NIHR. Males were recorded and discarded.

\section{Polymerase chain reaction species identification}

Polymerase chain reaction was carried out using deoxyribonucleic acid (DNA) extracted from two legs of each morphologically identified specimen. An. gambiae s.l. specimens were PCR-assayed using a protocol described by Scott et al. (1993) and amplified using specific diagnostic primers for An. gambiae, An. arabiensis and An. quadriannulatus. As for An. funestus group, samples were assayed following the methods of Koekemoer et al. (2002) with minor modifications as detailed by Spillings et al. (2009) using primers for An. funestus, An. leesoni, An. vaneedeni, An. parensis, An. rivulorum, An. rivulorumlike and An. funestus-like. The results of PCR amplification were visualized on $1 \%$ agarose gel by ethidium bromide staining.

\section{Data analysis}

Data were analysed using analysis of variance (ANOVA) at 95\% confidence limit. The relative abundance of the species was expressed as the percentage of the total number of Anopheles collected.

\section{Ethical considerations}

Confidentiality and voluntary participation was assured to the households members who were included for PSC. Signed informed consent form was obtained from each participant before collecting mosquitoes from the bedrooms.

\section{Results}

\section{Larval habitat census}

A total of 42 habitats positive for breeding of aquatic stages of mosquitoes were identified in the study areas (Figure 2). Rain pools were temporary, shallow wells, yam plantations and river banks were semipermanent, while irrigation channels as well as marshes were permanent mosquito habitats. Of these breeding sites, 23 were in Burma Valley and 19 in Zindi. For both study sites, the overwhelming majority of the anopheline-positive habitats were human-made $(88.1 \%, 37 / 42)$ with the remainder natural in origin $(11.9 \%, 5 / 42)$. Chances of sampling anopheline larvae were higher in irrigation channels in Zindi, but highly heterogeneous in yam plantations in Burma Valley area. All larval habitats were located within $2 \mathrm{~km}$ of the homesteads of both study sites.

\section{Larval habitat support and relative abundance}

Habitat support for larval development differed at the two study sites. In Burma Valley, 34.8\% (8/23) of the habitats had only anopheline, while $17.4 \%$ (4/23) had only culicine, and were visited 12 times. In Zindi, $15.8 \%$ (3/19) of the habitats had anopheline only and $36.8 \%$ (7/19) had only culicine, and were visited 10 times. This gave a com-
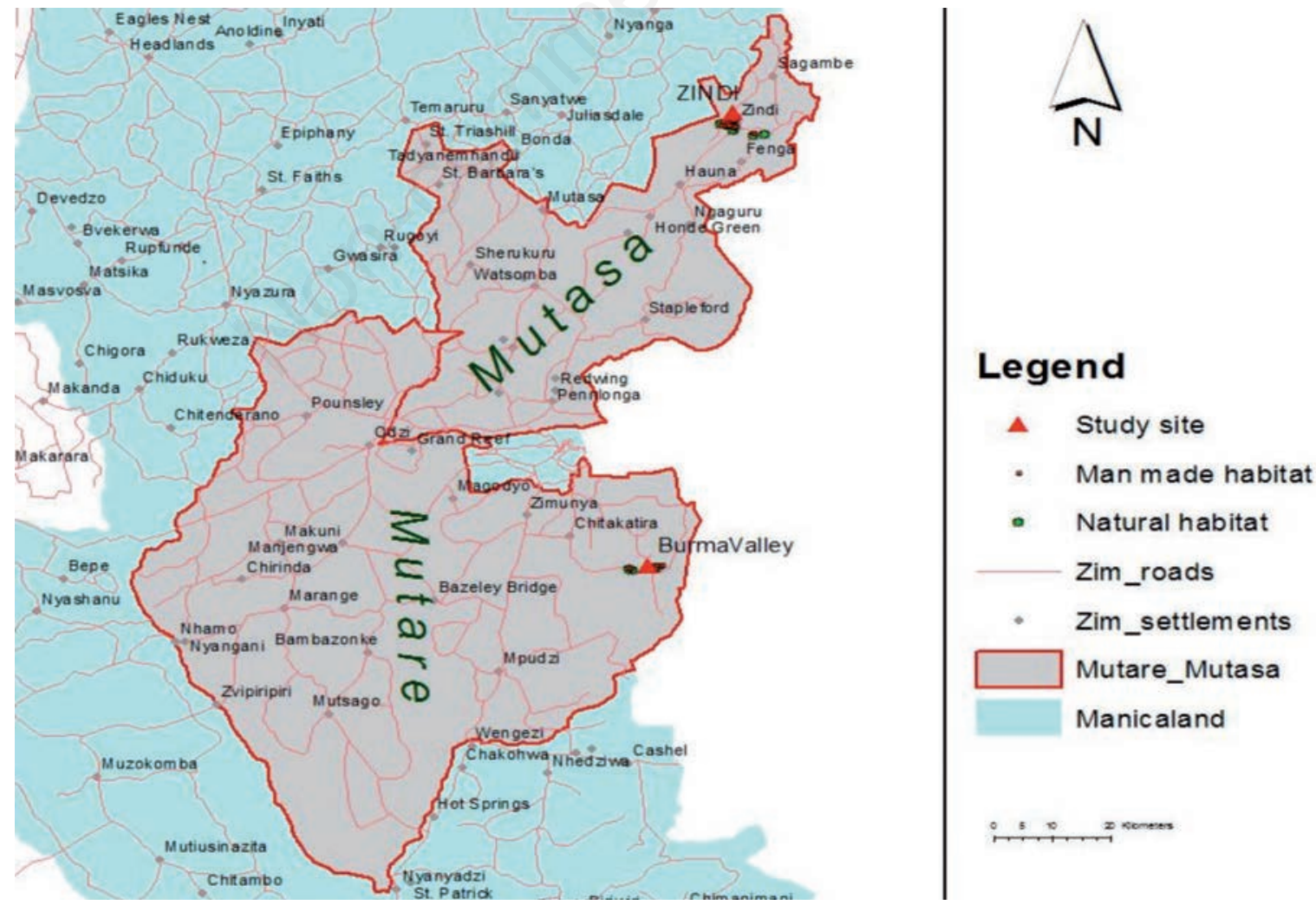

Figure 1. Map of Manicaland province, Zimbabwe, showing the study sites. 
bined total of 22 longitudinal samples in 12 months for the two study areas. Sympatry in anopheline and culicine larvae was found in $47.8 \%$ (11/23) of the habitats in Burma Valley and 47.4\% (9/19) in Zindi, suggesting that the mosquito larvae from the subfamilies Anophelinae and Culicinae coexist in almost half of the habitats.

A total of 3227 immature stages of anopheline larvae (2438 early instars, 789 late instar) were collected in Burma Valley and 1621 (872 early instars, 749 late instars) in Zindi. Pupae were observed in $28.6 \%$ (12/42) of larvae-positive sites. Anopheles larvae were more abundant in Burma Valley than in Zindi (ANOVA: $\mathrm{df}=6 ; \mathrm{F}=12.11 ; \mathrm{P}=0.00$ ). The mean density of Anopheles larvae over the entire sampling efforts was 4.2 and 1.8 larvae per dip in Burma Valley and Zindi, respectively. The majority of An. funestus larvae were collected in irrigation channels, marshes and shallow wells, whilst An. gambiae s.l. larvae were found in rain pools, yam plantations and river banks.

\section{Species composition of anopheline larvae}

Of the approximately 4848 Anopheles larvae collected, a total of 4690 adult mosquitoes emerged. From these, two malaria species complexes were morphologically identified, namely, An. funestus group and An. gambiae s.l. The An. funestus group accounted for $(1.9 \%, 87 / 4690)$ of the adults, while An. gambiae s.l. constituted (0.2\%, 10/4690), with An. pretoriensis, a non-malaria vector species contributing the majority $(97.9 \%, 4593 / 4690)$ in both study sites. Overall, the densities of adults of the An. funestus group and An. gambiae s.l. that emerged from the larval collections were low, but the An. funestus group was about 8 times more abundant than An. gambiae s.l.

\section{Species composition and abundance of adult Anopheles mosquitoes}

A total of 5625 Anopheles adults, including males and females were collected from larval sampling and indoors through PSC methods (Table 1). Of the total collections, An. pretoriensis was the most abundant while the remainder was shared between the An. funestus group and An. gambiae s.l. Overall, more anopheline mosquitoes were collected from aquatic stages (i.e., reared from larvae) than indoors (i.e., as adults), but indoor collections by PSC method had more malaria vector mosquitoes than larval collection. Of note, the results showed that the combined female An. funestus group and An. gambiae s.l. were approximately 5 times more abundant than males (Table 1).

\section{Species composition and abundance of female adult malaria vectors}

The species composition and the relative abundance of female malaria vector mosquitoes are presented in Table 2. Altogether, more than 800 female An. funestus group and An. gambiae s.l. mosquitoes were collected. As observed from Table 2, there was no difference in species composition in the two sites (ANOVA: $\mathrm{df}=1 ; \mathrm{F}=3.25 ; \mathrm{P}=0.17$ ), though the relative abundance of An. funestus group and An. gambiae

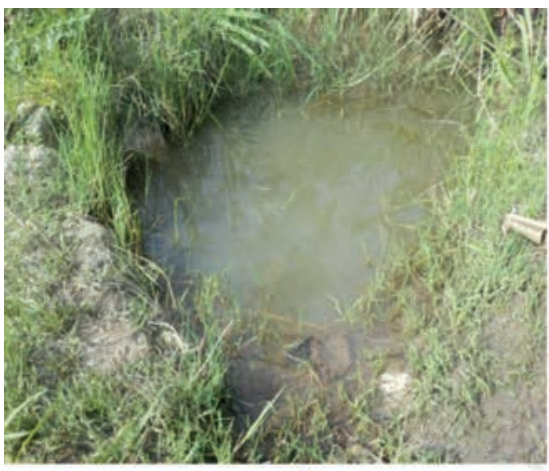

A

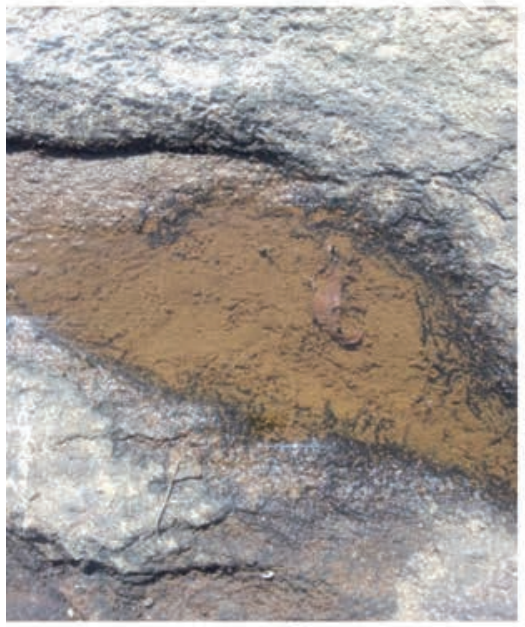

D

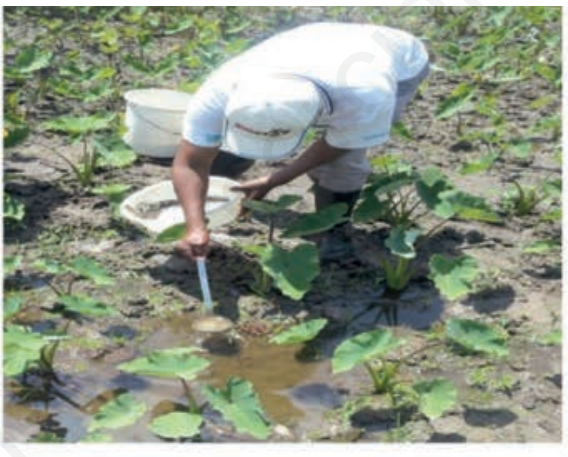

B

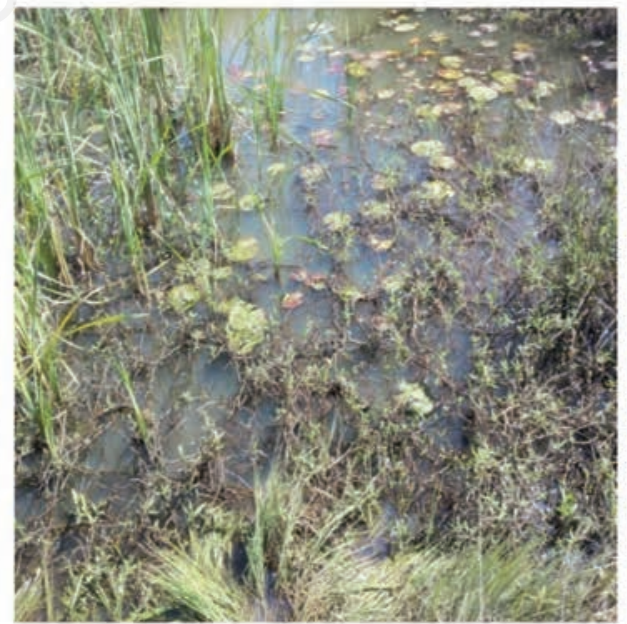

E

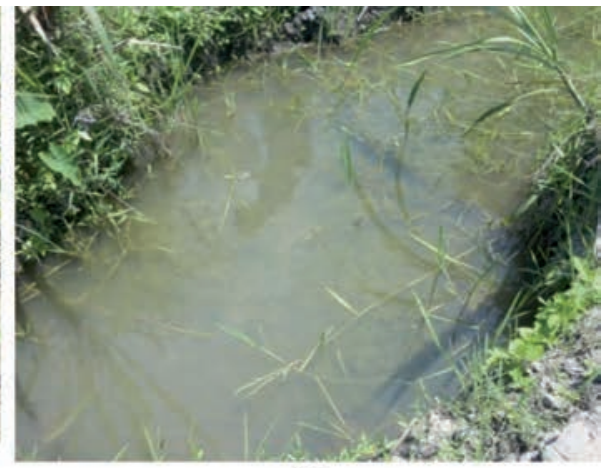

C

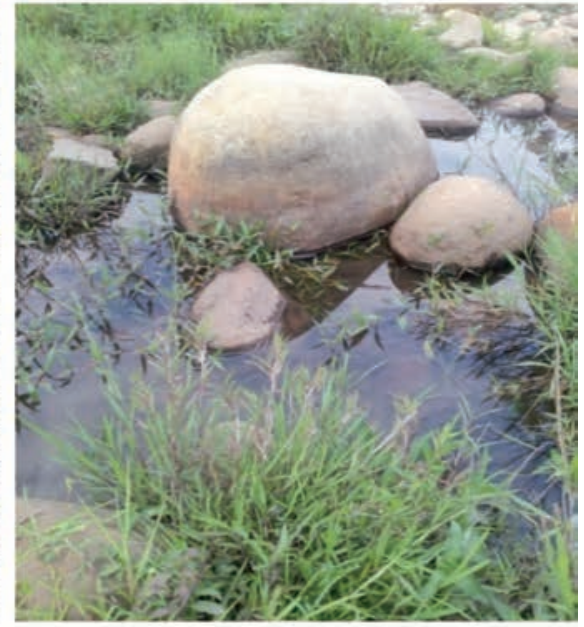

F

Figure 2. Types of mosquito breeding habitats in Burma Valley and Zindi, Mutare and Mutasa districts respectively, Zimbabwe: shallow well (A), yam plantation (B), irrigation channel (C), rain pool (D), marsh (E) and river bank (F). 
s.l. was more in Burma Valley than in Zindi (ANOVA: $\mathrm{df}=9 ; \mathrm{F}=3.65$; $\mathrm{P}=0.00$ ). All in all, members of the An. funestus group were 27 times more abundant than An. gambiae s.l. in both sites (Table 2).

\section{Polymerase chain reaction analysis of $A n$. funestus group sibling species}

From a total of 840 females that had been morphologically identified as members of the An. funestus group, 294 specimens were PCR assayed. Two sibling species were identified: An. funestus $(90.8 \%$, 267/294) at a position of 505 base pairs (bp) and An. leesoni (5.1\%, 15/294) at 146 bp (Figure 3). Twelve specimens (4.1\%, 12/294) failed to amplify after two replicates, though the positive control amplified successfully.

\section{Polymerase chain reaction based assays to identify sibling species of An. gambiae s.l.}

Out of a total of 31 females positively identified to be An. gambiae s.l., $48.4 \%$ (15/31) were identified as An. quadriannulatus while $41.9 \%$ (13/31) were An. arabiensis (Figure 4). About 9.7\% (3/31) of the An. gambiae s.l. tested could not be identified to specific species by PCR using the then available primers specific for An. gambiae, An. arabiensis and An. quadriannulatus sibling species.

\section{Percentage species composition and abundance of An. funestus and An. arabiensis in Burma Valley and Zindi}

An. funestus and An. arabiensis sibling species were present in both study sites, though both species were less abundant in Zindi than in Burma Valley (Table 3). The relative abundance of An. arabiensis was generally low in both sites. Overall, An. funestus was more abundant than An. arabiensis in both sites (ANOVA: $\mathrm{df}=2 ; \mathrm{F}=14.20 ; \mathrm{P}=0.02$ ) (Table 3).

\section{Discussion and conclusions}

The study showed the presence of two Anopheles complexes: An. gambiae and An. funestus in Burma Valley and Zindi. Both complexes contain important malaria vectors in sub-Saharan Africa (Coetzee et $a l ., 2000)$. Morphologically identified adults reared from larval collections revealed the presence of predominantly An. pretoriensis (a nonmalaria vector) and relatively low numbers of adults of the An. funestus group and An. gambiae s.l. The members of the An. funestus group were, however, relatively more abundant than members of An. gambiae

Table 1. Percentage mosquito species composition sampled in Burma Valley and Zindi as identified by morphological means (actual numbers in parentheses).

\begin{tabular}{|c|c|c|c|c|c|c|c|}
\hline \multirow[t]{2}{*}{ Sampling method } & \multirow[t]{2}{*}{ Study area } & \multirow[t]{2}{*}{$\mathbf{N}$} & \multicolumn{2}{|c|}{ An. funestus group } & \multicolumn{2}{|c|}{ An. gambiae s.l. } & \multirow[t]{2}{*}{ An. pretoriensis } \\
\hline & & & Male & Female & Male & Female & \\
\hline \multirow[t]{2}{*}{ PSC } & Burma Valley & 795 & 16.0 & 80.6 & 0.5 & 2.8 & 0.1 \\
\hline & Zindi & 140 & 9.3 & 87.1 & 0.7 & 2.9 & 0 \\
\hline \multirow[t]{2}{*}{ RFL } & Burma Valley & 3141 & 0.3 & 1.1 & 0.1 & 0.1 & 98.4 \\
\hline & Zindi & 1549 & 0.1 & 2.8 & 0.1 & 0.1 & 96.9 \\
\hline Total & & 5625 & 2.6 & 14.9 & 0.2 & 0.6 & 81.7 \\
\hline
\end{tabular}

PSC, pyrethrum spray catch; RFL, reared from larvae.

Table 2. Species composition (\%) and abundance of An. funestus group and An. gambiae s.l. adult females by sampling method in Burma Valley and Zindi areas (count data in parentheses).

\begin{tabular}{|c|c|c|c|c|}
\hline Sampling method & Study area & Total number & An. funestus group & An. gambiae s.l. \\
\hline PSC & $\begin{array}{c}\text { Burma Valley } \\
\text { Zindi }\end{array}$ & $\begin{array}{l}663 \\
126\end{array}$ & $\begin{array}{l}96.7(641) \\
96.8(122)\end{array}$ & $\begin{array}{l}3.3(22) \\
3.2(4)\end{array}$ \\
\hline RFL & $\begin{array}{c}\text { Burma Valley } \\
\text { Zindi }\end{array}$ & $\begin{array}{l}37 \\
45 \\
\end{array}$ & $\begin{array}{l}91.9(34) \\
95.6(43)\end{array}$ & $\begin{array}{l}8.1(3) \\
4.4(2)\end{array}$ \\
\hline Total & & 871 & $96.4(840)$ & $3.6(31)$ \\
\hline
\end{tabular}

PSC, pyrethrum spray catch; RFL, reared from larvae.

Table 3. Percentage of species composition and abundance of An. funestus and An. arabiensis in Burma Valley and Zindi areas (count data in parentheses).

\begin{tabular}{lccc} 
Study area & Total number & An. funestus & An, arabiensis \\
Burma Valley & 169 & $95.3(161)$ & $4.7(8)$ \\
Zindi & 111 & $95.5(106)$ & $4.5(5)$ \\
\hline Total & 280 & $95.4(267)$ & $4.6(13)$ \\
\hline
\end{tabular}


s.l. (ANOVA: $\mathrm{df}=4 ; \mathrm{F}=4.44 ; \mathrm{P}=0.04$ ). These findings are consistent with previous studies in Zimbabwe that demonstrated dominance of An. pretoriensis reared from larvae over other anopheline species (Masendu et al., 2005).

This study clearly showed that malaria vectors belonging to the $A n$. funestus group and An. gambiae s.l. breed in sympatry in the study sites. Most of the mosquito larval habitats in the study areas are humanmade; suggesting that malaria transmission in the study areas is derived mainly from human modification and manipulation of the ecosystem. While the irrigation facilities are important to sustain food security, mitigating measures need to be put in place to minimize breeding of vector mosquitoes.

In the present study, members of the An. funestus group were more abundant than members of An. gambiae s.l. from both adult and larval collections. Previous work by Mpofu (1985), Taylor and Mutambu (1986) and Masendu et al. (2005) had shown members of An. gambiae s.l. to be the more abundant malaria vector in Zimbabwe.

Using PCR, the present study identified two species: An. funestus and $A n$. arabiensis that transmit malaria in the study sites. PCR identification of sibling species of the An. funestus group and An. gambiae s.l. is of great importance to the malaria control programme in Zimbabwe. Molecular analysis of the An. funestus group established the presence of An. funestus and An. leesoni. This is in agreement with studies by Oyewole et al. (2005) but in contrast with other previous studies in Africa which recorded An. funestus in sympatry with minor vectors $A n$. rivulorum and An. leesoni (Wilkes et al., 1996). The failure to amplify $5.1 \%$ of the An. funestus group could be due to morphological misidentification of some specimens and/or emergence of other sibling species.

Meanwhile, PCR assay of An. gambiae s.l. also revealed two common members: An, quadriannulatus and An. arabiensis, but could not exclude the possibility that other members of the complex might be

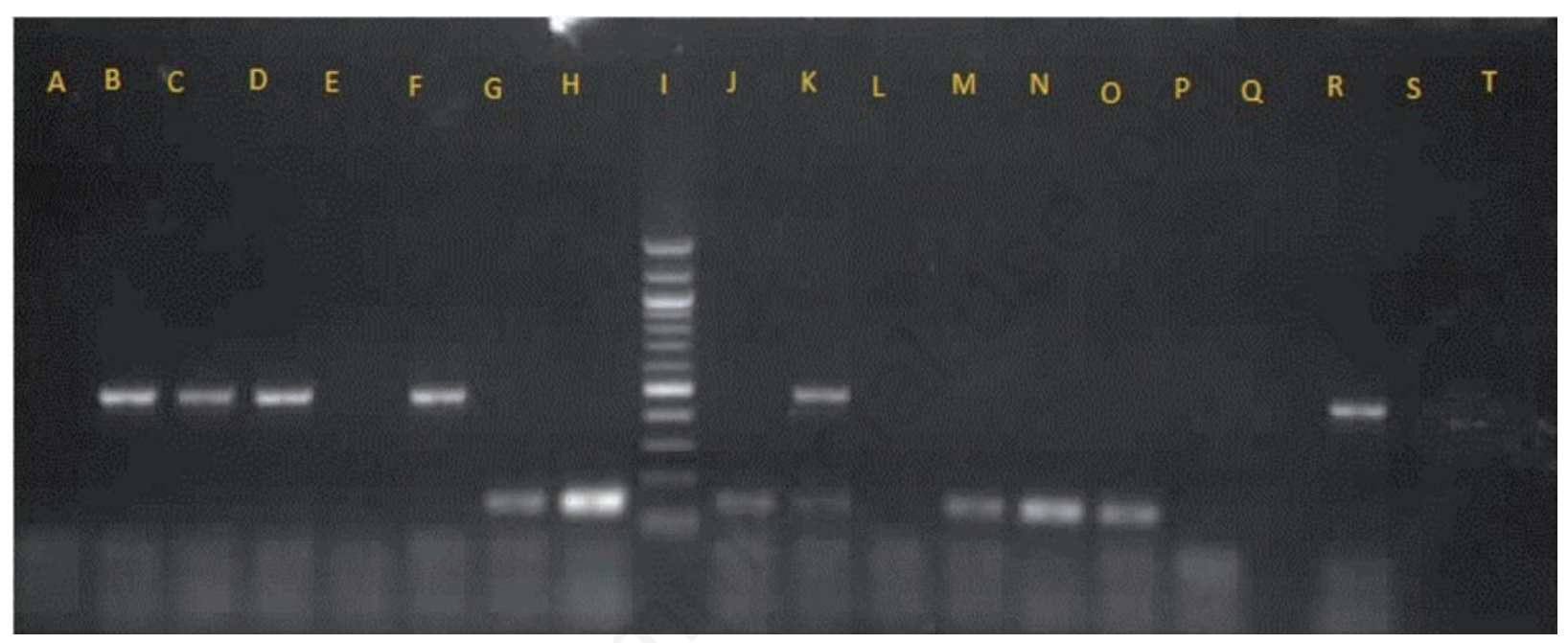

Figure 3. Identification of members of $A n$. funestus group from Burma Valley and Zindi: negative control (lane A), positive control (lane B), 100 base pair molecular ladder (lane I), An. funestus (505 base pair) (lanes C, D, F and R), An. leesoni (146 base pair) (lanes G, H, $\mathrm{J}, \mathrm{M}, \mathrm{N}$ and $\mathrm{O})$, An. funestus and An. leesoni mixed DNA (lane K), no amplification (lanes E, L, P, Q, S and T).

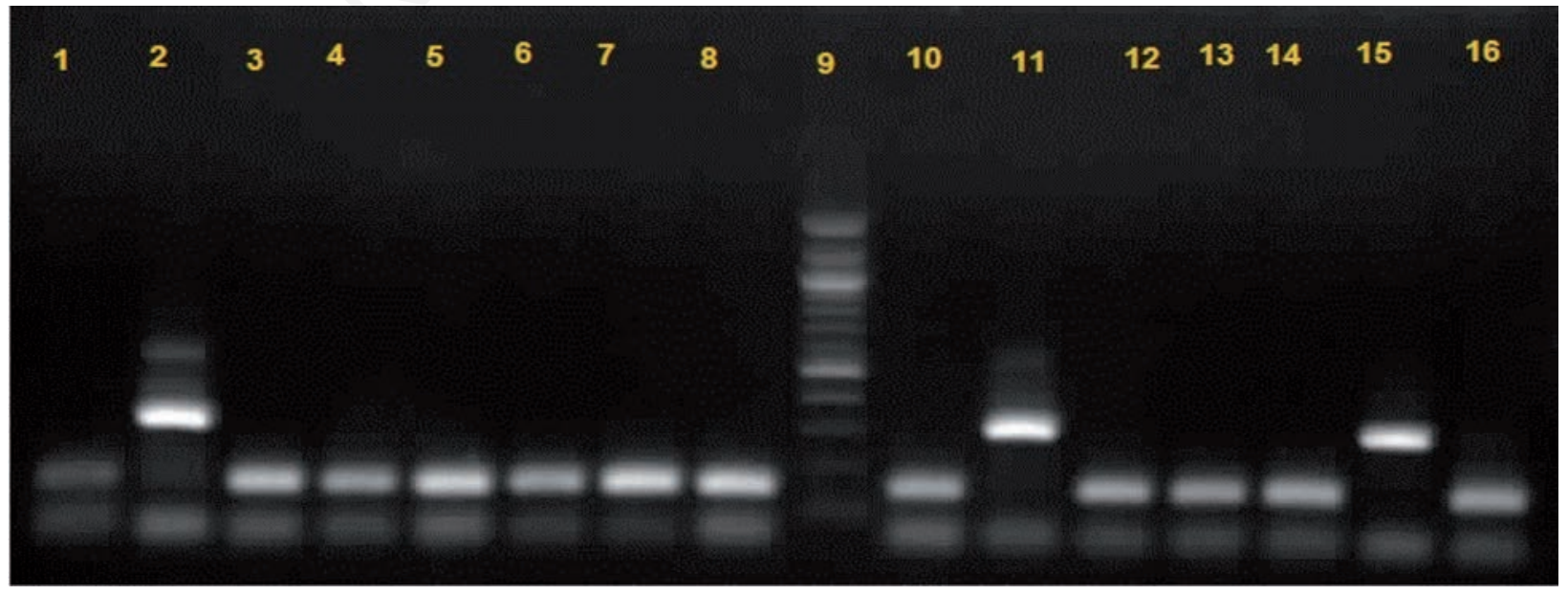

Figure 4. Species identification of members of An. gambiae s.l. from Burma Valley and Zindi: An. quadriannulatus (150 base pair) (lanes 1,3-8, 10, 12-14 and 16), An. arabiensis (315 base pair) (lanes 2, 11 and 15), 100 base pair molecular marker (lane 9). 
amongst the specimens (9.7\%) that failed to amplify. It is likely that the unidentified An. gambiae s.l. could be An. merus as the protocol by Scott et al. (1993) used in this study did not include primers to identify $A n$. merus which Masendu et al. (2005) reported as being common in some parts of Zimbabwe.

Polymerase chain reaction assays revealed An. funestus to be more abundant than An. arabiensis, confirming the status of the former as a major malaria vector mosquito in both sites. This is in sharp contrast with results from work by Mpofu (1985), Taylor \& Mutambu (1986) and Masendu et al. (2005) which had shown An. arabiensis to be a primary vector while An. gambiae and An. funestus were secondary vectors in Zimbabwe. The sharp increase in An. funestus population in the presence of IRS implementation in this study sites cannot be explained in this study. It is more likely that pyrethroid-resistant An. funestus survived undetected while An. arabiensis and to a larger extent, An. gambiae, remained susceptible to pyrethroids which have been used for IRS and treatment of LLINs over the years in the study areas.

In general, species replacement for various reasons, especially as a result of IRS and LLINs is not a new phenomenon (Kitau et al., 2012). Recent data from East Africa showed changes in sibling species following the scaling-up of ITNs/LLINs, with An. arabiensis becoming the dominant species in habitats that previously supported sympatric $A n$. gambiae and An. arabiensis populations (Kitau et al., 2012). A similar change in species composition and abundance was reported during the implementation of IRS in Zimbabwe; example being the observation of An. funestus in most parts of Zimbabwe by Mpofu (1985), which was isolated in later studies by Masendu et al. (2005) only at Buffalo Ranch in Chiredzi district.

As revealed by the findings of this study, heterogeneity of vector species composition and dominance of An. funestus is of major significance in malaria control. The results have important implications for malaria epidemiology and control given that An. funestus is a more efficient vector than An. arabiensis. Low densities of An. funestus have the potential to sharply increase levels of malaria transmission (Morgan et al., 2010).

This study also revealed that there is information gap on the resting, biting and insecticide susceptibility status of malaria vectors in the study sites. The information is crucial for planning, implementation and evaluating malaria vector control strategies. Additionally, the emergence/upsurge of An. funestus in areas under IRS and LLINs use requires urgent attention to prevent possible malaria outbreaks. Mitigation measures for irrigation projects or farming should be put in place to minimize malaria vector breeding.

\section{References}

CHOI K.S., CHRISTIAN R., NARDINI L., WOOD O.R., AGUBUZO E., MULEBA M., MUNYATI S., MAKUWAZA A., KOEKEMOER L.L., BROOKE B.D., HUNT R.H., COETZEE M., 2014 - Insecticide resistance and role in malaria transmission of Anopheles funestus populations from Zambia and Zimbabwe. - Parasit vectors. 7: 464.

COETZEE M., CRAIG M., LE SUEUR D., 2000 - Distribution of African malaria mosquitoes belonging to the Anopheles gambiae complex. - Parasitol. Today. 16: 74-77.

COHUET A., SIMARD F., TOTO J.C., KENGNE P., COETZEE M., FONTENILLE D., 2003 - Species identification within the Anopheles funestus group of malaria vectors in Cameroon and evidence for a new species. - Am. J. Trop. Med. Hyg. 69: 200-205.

COLUZZI M., 1984 - Heterogeneities of the malaria vectorial system in tropical Africa and their significance in malaria epidemiology and control. - Bull. World Health Organization 62: 107-113.

GILLIES M.T., COETZEE M., 1987 - A supplement to the Anophelinae of
Africa south of the Sahara (Afro tropical Region). - South Africa Institute for Medical Research, Johannesburg. Publications of the South Africa Institute for Medical Research: 55.

GILLIES M.T., DE MEILLON B., 1968 - The Anophelinae of Africa south of the Sahara. - South Africa Institute for Medical Research, Johannesburg. Publications of the South Africa Institute for Medical Research: 54 .

GREGORY C.L., YOOSOOK L., 2013 - Speciation in Anopheles gambiaethe distribution of genetic polymorphism and patterns of reproductive isolation among natural populations. - InTech. Available from: http://dx.doi.org/10.5772/56232

KITAU J., OXBOROUGH R.M., TUNGU P.K., MATOWO J., MALIMA R.C., MAGESA S.M., BRUCE J., MOSHA F.W., ROWLAND M.W., 2012 Species shifts in the Anopheles gambiae complex: Do LLINs successfully control Anopheles arabiensis? - PloS One 7: e31481.

KOEKEMOER L.L., KAMAU L., HUNT R.H., COETZEE M., 2002 - A cocktail polymerase reaction assay to identify members of the Anopheles funestus (Diptera: Culicidae) group. - Am. J. Trop. Med. Hyg. 66: 804-811.

LUKWA N., SANDE S., MAKUWAZA A., CHIWADE T., NETSA M., ASAMOA K., VAZQUEZ-PROKOPEC G., REITHINGER R., WILLIAMS J., 2014 Nationwide assessment of insecticide susceptibility in Anopheles gambiae populations from Zimbabwe. - Malaria J. 13: 408.

MASENDU H.T., HUNT R.N., KOEKEMOER L.L., BROOKE B.D., 2005 Spatial and temporal distributions and insecticide susceptibility of malaria vectors in Zimbabwe. - Afr. Entomol. 13: 25-34.

MOLINEAUX L., GRAMICCIA G., 1980 - The Garki project: Research on epidemiology and control malaria in the Sudan Savanna of West Africa. - World Health Organization. Geneva, Switzerland. Available from: http://garkiproject.nd.edu/static/documents/garkiproject.pdf

MORGAN J.C., IRVING H., OKEDIV L.M., STEVEN A., WONDJI C.S., 2010 - Pyrethroid resistance in an Anopheles funestus population from Uganda. - PloS One 29: e11872.

MPOFU S.M., 1985 - Seasonal vector density and disease incidence pattern in an area of Zimbabwe. - Trans. R. Soc. Trop. Med. Hyg. 79: 169-175.

MUNHENGA G., 2010 - Characterization of resistance mechanisms in the major malaria vector Anopheles arabiensis from southern Africa. PhD Thesis University of Witwatersrand, South Africa: 5-12.

OYEWOLE I. 0., IBIDAPO A.C., ODUOLA A.O., OBANSA J.B., AWOLOLA S.T., 2005 -Molecular identification and population dynamics of the major malaria vectors in a rainforest zone of Nigeria. - Nigerian Soc. Exp. Biol. 17: 171-178.

SCOTT J.A., BROGDON W.G., COLLINS F.H., 1993 - Identification of single specimens of the Anopheles gambiae complex by the Polymerase Chain Reaction. - Am. J. Trop. Med. Hyg. 49: 520-529.

SPILLINGS B.L., BROOKE B.D., KOEKEMOER L.L., CHIPHWANYA J., COETZEE M., HUNT R.H., 2009 - A new species concealed by Anopheles funestus Giles, the major malaria vector in Africa. - Am. J. Trop. Med. Hyg. 81: 510-515.

TAYLOR P., MUTAMBU S.L., 1986 - A review of the malaria situation in Zimbabwe with special reference to the period 1972-1981. - Trans. R. Soc. Trop. Med. Hyg. 80: 12-19.

WHO, 2003 - Malaria entomology and vector control. Learners' Guide. WH0/CDS/CPE/SMT/2202.18 Rev.1 Part 1. - World Health Organization, Geneva.

WHO, 2013 - An operational manual for indoor residual spraying for malaria transmission control and elimination. - World Health Organization, Geneva. Available from: http://www.int/malaria/publications/atoz/9789241505123/en

WILKES T.J., MATOLA Y.G., CHARLWOOD J.D., 1996 - Anopheles rivulorum, a vector of human malaria in Africa. - Med. Vet. Entomol. 10: 108-110. 